\title{
O Uso do Excel no Tratamento da Informação: Relação com os Saberes e as Dificuldades dos Docentes em Formação
}

\author{
Alex P. Silva, Sônia R. F. Silva \\ Universidade de Pernambuco, Campus Garanhuns (UPE) \\ CEP 55.294 - 902 - Garanhuns - PE - Brasil \\ \{alexcomputersilva, fortes.sonia\}@gmail.com
}

\begin{abstract}
This article presents a discussion and analysis of training knowledge and experience and the difficulties faced by teachers in training, a Bachelor's Degree in Mathematics with Excel use in teaching statistics. The data to characterize the knowledge and the difficulties of the research were obtained through questionnaires, basing the analysis through studies in the literature that deal with the teacher's knowledge. Through the demands analyzed, there is the expectation that training courses can treat this tool in teaching situations with teachers in training, giving greater security both to those who already use it and those who do not know how to use it in teaching situations.
\end{abstract}

Resumo. Este artigo apresenta a discussão e analise dos saberes da formação e da experiência e as dificuldades encontradas por professores em formação, de um curso de Licenciatura em Matemática, com o uso do Excel no ensino de Estatística. Os dados para caracterizar os saberes e as dificuldades nesta pesquisa foram obtidos por meio de questionários, fundamentando a análise através de trabalhos na literatura que tratam sobre os saberes docentes. Através das demandas analisadas, tem-se a expectativa de que cursos de formação possam tratar esta ferramenta em situações didáticas com os professores em formação, atribuindo uma maior segurança tanto aos que já a utilizam e aos que não sabem utilizá-la em situações de ensino.

\section{Introdução}

As transformações ocorridas em diversos setores da sociedade, com um mundo cada vez mais cercado por tecnologia, estão modificando a forma como o homem se comunica, se relaciona, como aprende. Com o avanço tecnológico que toma conta da sociedade, a escola possui a responsabilidade de provocar a participação de alunos em experiências inovadoras e de interação com as diferentes mídias que são disponibilizadas socialmente, como destaca Guimarães (2012).

Saber utilizar as ferramentas computacionais representa uma prática alternativa para professores de Matemática (GUIMARÃES, 2012) contribuindo para a produção/aquisição dos saberes que, muitas vezes estão ausentes em sua formação (SILVA, 2005). Nesse contexto, saber utilizar essas ferramentas em sua prática é um meio de preparar os jovens para sua inserção no mercado de trabalho, como também desenvolver neles habilidades na interpretação de gráficos, no ensino de Estatística, por meio da planilha de cálculos do Office - Excel (CAMPELLO, 2014), realização de cálculos, de uma forma rápida, a partir dos dados informados e, posteriormente, a elaboração de diferentes modalidades de gráficos facilitando a visualização das informações (TAJRA, 2001). 
Diante do exposto, percebe-se que o uso de artefatos computacionais no ensinoaprendizagem é uma demanda sócio-educativa. Este trabalho apresenta resultados de uma pesquisa que buscou investigar a aplicação do Excel no ensino de Estatística, abrindo a discussão com professores de Matemática em formação, sobre a construção dos saberes docentes necessários ao uso didático-pedagógico do Excel para a aplicação de conceitos de estatística, nos anos finais do ensino fundamental, e as dificuldades encontradas por estes profissionais, através da análise dos fatores limitadores da formação.

Este artigo está estruturado da seguinte maneira: na seção dois apresenta-se o resultado de um levantamento bibliográfico feito sobre o potencial técnico do Excel. A seção de número três aborda as demandas de saberes docentes dos professores necessários às exigências das matrizes curriculares de Matemática aos conhecimentos escolares. Na seção quatro, destaca-se a metodologia aplicada na pesquisa, que possibilitou identificar os saberes e os desafios encontrados pelos participantes da pesquisa, em utilizar ou não, o Excel, em sala de aula. Na seção cinco é apresentada a análise dos dados apresentado pelos docentes em formação. $\mathrm{Na}$ última seção, são apresentadas as considerações finais acerca da pesquisa.

\section{O Potencial Técnico do Excel para a Prática Pedagógica dos Professores no Tratamento da Informação no Ensino de Estatística}

$\mathrm{Na}$ busca por inserir as tecnologias na educação, o professor precisa estar preparado para utilizar as ferramentas tecnológicas que são inseridas na sala de aula. Aprender a utilizar ferramentas, como por exemplo, os principais recursos do pacote Office, entre eles, a Microsoft Excel, apresenta-se como uma possibilidade na prática docente (TAJRA, 2001).

Este programa do pacote Office e os demais existentes ${ }^{1}$, não foram desenvolvidos com finalidades educativas. São ferramentas cuja concepção está direcionada mais para o contexto de empresas. Apesar de não terem sidos desenvolvidos com finalidades educativas, estes softwares podem ser utilizados para este objetivo (TAJRA, 2001), sendo denominados de softwares educacionais. Entre eles destacam-se: a planilha eletrônica, editores de texto e de apresentação.

A utilização do Excel com finalidade educacional pode ser aplicada em diferentes áreas do conhecimento. Diversas pesquisas apresentam a aplicação desta ferramenta no ensino de Estatística e em outras áreas do conhecimento como a Matemática Financeira, Engenharia, entre outras.

Campello (2014) apresenta o Excel como uma importante ferramenta computacional no auxílio à prática dos professores na exploração de certos conteúdos matemáticos como: médias, estudo de matrizes, determinantes, noções de estatística e teoria dos conjuntos, possibilitando um reforço desses conteúdos, implicando também em uma melhoria na visualização das fórmulas.

Trabalhos como o de Prietch (2009) apresentam resultados de experiências com a aplicação do computador, com suporte de um software de planilha eletrônica, o Excel, na simulação de dados através de modelos estatísticos e probabilísticos, com o objetivo

\footnotetext{
1 Também fazem parte do programa do pacote Office os programas Microsoft Word, Excel, Power Point, entre outros.
} 
de aumentar a compreensão dos alunos no processo de ensino aprendizagem nas áreas de Engenharia.

Professores buscaram inserir diferentes TIC no ensino, entre elas o Excel, visando contribuir para o processo de aprendizagem, na disciplina de Métodos Quantitativos em Administração, com o intuito de despertar o interesse dos alunos pelo conteúdo, como também o estudo de conceitos que norteiam a Educação Estatística, entre eles, Frequência Relativa, Frequência Percentual e Frequência Cumulativa, Gráficos de Barras e Colunas, e Histograma (SILVA, 2013).

O trabalho de Ferreira et al. (2014) apresentam o resultado de uma pesquisa aplicando uma metodologia específica, com o uso da planilha eletrônica do Excel no ensino de matemática financeira, através de situações-problema, na qual foram abordados conceitos de capitalização simples e composta e descontos simples.

Pereira et al. (2013), na expectativa de agilizar os processos de cálculo e a elaboração de tabelas e gráficos, buscaram tornar mais fácil o entendimento do assunto em Distribuição de Probabilidade Normal nas aulas de Estatística com alunos do Curso de Química Industrial. Utilizaram como ferramenta de apoio o aplicativo Microsoft Excel, constatando ao final dessa pesquisa que com a utilização de algumas funções especiais desta ferramenta, conjuntamente com os conceitos teóricos sobre o tema, os alunos tiveram uma significativa melhora no entendimento do assunto.

Os Parâmetros Curriculares Nacionais (PCN) também destacam a importância dos alunos saberem fazer uso das ferramentas computacionais, na realização de determinadas atividades. No Ensino de Estatística, estas ferramentas integradas aos computadores, como a planilha eletrônica, servem de apoio para a realização de atividades que envolvem o tratamento da informação. Nesse sentido, no momento em que o aluno tem a possibilidade em utilizar o computador na realização das suas atividades, aumenta a possibilidade do mesmo em compreender e utilizar esses recursos tecnológicos para a resolução de problemas fora da escola (BRASIL, 1998).

\section{Saberes Docentes Necessários ao Repertório dos Professores para Construir Situações de Ensino com os Conceitos Estatísticos}

De acordo com Lopes (1998), a formação básica em Estatística torna-se indispensável ao cidadão, para o exercício da cidadania, não apenas nos dias atuais, como também, em tempos futuros. Cabe ao professor no ensino da Matemática não apenas o compromisso de ensinar o domínio dos números, mas também a organização de dados e leitura de gráficos (LOPES, 1998).

Em função da demanda social, há no currículo de Matemática, o trabalho de temas que incluem, a partir do ensino fundamental, o estudo da estatística (BRASIL, 1998). Esta habilidade envolve a capacidade do aluno em interpretar gráficos e tabelas, possibilitando, assim, tomada de decisões na resolução e compreensão de problemas.

Nesse contexto, as situações de ensino-aprendizagem nas escolas passam a exigir novas demandas dos saberes dos professores com relação à utilização das ferramentas, que por ora, foram concebidos para fins não educacionais, mas que passam a ocupar o espaço de sala de aula provocando, de acordo com Silva (2012, p. 14) "inquietações naqueles que atuam na educação e, principalmente, no corpo docente que enfrenta o uso dos computadores no ensino". 


\section{CBIE-LACLO 2015}

Anais dos Workshops do IV Congresso Brasileiro de Informática na Educação (CBIE 2015)

De acordo com Correa (2013) os saberes docentes são constituídos a partir de um conjunto complexo de condições. Eles advêm de diferentes áreas, como os conhecimentos didáticos adquiridos na formação do professor, os saberes dos conteúdos pedagógicos, os saberes da experiência (PIMENTA, 1999, apud CORREA, 2013). No caso, fez parte desta pesquisa, identificar quais são os saberes presentes na prática do professor que faz uso do Excel no ensino de Estatística, e como estes foram construídos para que os docentes tivessem condições de construir uma aula com os recursos informáticos, além das dificuldades encontradas pelos mesmos em não fazer uso desta ferramenta em situações de ensino.

Professores acabam descobrindo na prática que, para fazer uso dos recursos informáticos disponíveis nos computadores das escolas, além de ter que dominar os conteúdos, deveriam ter construído, no momento da sua formação inicial, os saberes para utilizar as ferramentas disponíveis para fins educativos (SILVA, 2005). Nesse sentido, as tecnologias desafiam os professores a produzirem novos repertórios e reservatórios de saberes e conhecimentos docentes (SILVA, 2012).

Essa questão direciona a atenção para os cursos de formação desses profissionais, como aponta Teixeira (2002), ao destacar que "quanto mais plural precisa ser, maior se torna a responsabilidade da sua formação". Esta formação será norteadora para que o professor construa os saberes que vão influenciar em suas decisões em sala de aula com o uso do computador, como suporte didático.

Pimenta (2012, p. 37), afirma que "o exercício de qualquer profissão é técnico, no sentido de que é necessária a utilização de técnicas para executar as operações e ações próprias". Para isso, exige-se desse profissional, habilidade para manusear os instrumentos informáticos a seu favor, no ensino de determinado conceito da área de conhecimento matemático. Nesse sentido, constata-se que muitas vezes as habilidades para manusear as ferramentas informáticas não são suficientes para a resolução dos problemas com os quais se defrontam (PIMENTA, 2012).

A articulação dessas tecnologias no contexto da sala de aula exige do docente refletir sobre o que fazer e demanda uma atualização dos seus conhecimentos para utilizar novos enfoques em situações de ensino (SILVA, 2012). De acordo com Silva (2012), o professor sente-se desafiado em seus saberes ao ter que utilizar, por exemplo, os recursos disponíveis nos programas de computador, ao ter que planejar uma aula fazendo uso destes recursos e provocar aprendizagem na sala de aula. Os saberes mobilizados pelos professores na utilização das ferramentas informáticas para situações de ensino aprendizagem podem estar ausentes no momento de formação do professor sendo construídos ao longo do exercício da profissão.

\subsection{Saberes Docentes da Formação e da Experiência}

Tardif (2010) caracteriza os saberes docentes como sendo plural advindo de diferentes fontes. A seguir busca-se apresentar de forma sucinta, alguns destes saberes que integram os saberes docentes, fundamentando, assim, esta pesquisa:

- Saberes da formação profissional: caracteriza-se como o conjunto de saberes transmitidos pelas instituições de formação inicial e continuada de professores, sendo incorporado a prática docente.

- Saberes das disciplinas: correspondem aos saberes das disciplinas dos cursos de formação inicial e continuada. 
- Saberes da experiência: também conhecidos como saberes da prática, são o conjunto de saberes que não provêm das instituições de formação nem dos currículos. Estes são construídos no seu trabalho cotidiano, exercício docente, da experiência do professor, no meio em que está inserido.

Silva (2005) apresenta outros tipos de saberes, relevantes para fundamentar esta pesquisa, a saber: saberes informáticos e saberes didáticos informáticos:

- Saberes informáticos: estes saberes relacionam-se sobre o domínio das ferramentas dos programas do computador.

- Saberes didáticos informáticos ou saberes didáticos do uso do computador: estes saberes possibilitam aos docentes aplicar o computador, visando à melhor compreensão dos alunos ao trabalhar os conteúdos disciplinares.

\section{Metodologia}

A opção metodológica para a pesquisa caracterizou-se como pesquisa qualitativa exploratória definida por Richardson (1999, p.90), como "a tentativa de uma compreensão detalhada dos significados e características situacionais apresentadas pelos entrevistados, em lugar da produção de medidas quantitativas de características ou comportamentos".

$\mathrm{Na}$ primeira etapa do processo de investigação, destaca-se uma sondagem em relação ao uso ou não das ferramentas informáticas no ensino de Estatística pelos professores de Matemática em formação, do curso de Licenciatura em Matemática, da Universidade de Pernambuco, Campus Garanhuns, além da realização do levantamento bibliográfico e documental, bem como entrevistas em estudo de caso (GIL, 2008).

Caracteriza-se como professores em formação inicial, estudantes concluintes do curso de Licenciatura em Matemática que já exerceram ou exercem a atividade docente em escolas públicas ou privadas através de minicontratos, vivenciando as atividades letivas em sala de aula com discentes dos anos finais do ensino fundamental e médio, em Garanhuns e cidades circunvizinhas do agreste pernambucano.

Para a obtenção dos dados referentes aos saberes e dificuldades inerentes à formação docente voltado ao uso da planilha eletrônica, o Excel, e posteriormente uma análise e discussão dos mesmos, utilizou-se como instrumento, o questionário.

Os entrevistados selecionados para a pesquisa cursavam o $8^{\circ}$ período do curso de Licenciatura em Matemática, na Universidade de Pernambuco (UPE), Campus Garanhuns. Foram entrevistados 8 alunos, sendo 5 do gênero feminino e 3 do gênero masculino. Para a seleção destes, levou-se em consideração que os mesmos deviam estar em atuação em seu exercício profissional.

O quadro 1 apresenta as perguntas do questionário aplicados aos professores em formação inicial que não sabem utilizar o Excel, objetivando o levantamento de dados referentes as dificuldades dos participantes e posteriormente uma análise dos mesmos.

Quadro 1. Perguntas direcionadas aos professores que não utilizam o Excel no ensino de Matemática

1 - O que você considera que precisa aprender sobre o programa Excel para utilizá-lo no ensino de Matemática?

2 - Que saídas você tem encontrado no seu exercício docente para ensinar Estatística sem o uso do Excel? 
CBIE-LACLO 2015

Anais dos Workshops do IV Congresso Brasileiro de Informática na Educação (CBIE 2015)

3 - Qual a consequência de não saber utilizar o Excel para a sua docência?

4 - Considera que existe diferença em ensinar Estatística com e sem o Excel para os alunos? Justifique.

5 - Já que você não utiliza o Excel no ensino de Matemática, utiliza outro software nesta disciplina? Qual (is)?

O quadro 2 apresenta as perguntas direcionadas aos professores que utilizaram ou utilizavam o Excel como ferramenta auxiliar no ensino de Estatística.

\section{Quadro 2. Perguntas direcionadas aos professores que utilizam o Excel no ensino de Matemática}

1 - Você usa com segurança técnica e pedagógica o Excel em sala de aula com os seus alunos? Justifique

2 - Como aprendeu a usar o programa?

3 - Em quais conteúdos de Matemática você utiliza o Excel?

4 - Você sente dificuldade ao utilizar esse programa como apoio ao processo de ensino aprendizagem? Caso haja essa dificuldade, você consideraria esta quanto ao conteúdo, a metodologia ou a visão técnica do Excel? Justifique.

5 - Você usou o Excel em sua formação em licenciatura? Caso seja sim, em quais conteúdos e disciplinas?

6 - Considera que existe diferença em ensinar Estatística com e sem o Excel para os alunos? Justifique.

7 - Além do Excel, existe outro(s) programa(s) que você utiliza no ensino da Matemática? Qual(is)?

A interpretação dos dados utilizada baseou-se no modelo proposto por Bardin (1988) denominado análise de conteúdo. Nesta proposta buscou-se compreender determinado tema, "apresentado pela comunicação verbal, falada e/ou escrita, tendo como objeto a linguagem, realçando o sentido que se encontra em primeiro e segundo plano" (BARDIN, 1988 apud SILVA, 2011, p. 50).

Nesse sentido, por meio das respostas apresentadas pelos participantes, mais a fundamentação teórica de autores como Tardif (2010) e Silva (2005), e o modelo de análise de conteúdos citado anteriormente, foi possível caracterizar os saberes dos docentes em formação e da experiência como também a dificuldade dos mesmos para o uso do Excel no Tratamento da Informação, com o uso do Microsoft Excel, no ensino de Estatística nas séries finais do ensino fundamental.

\section{Análise dos Resultados}

A seguir, apresenta-se a análise dos dados obtidos na pesquisa.

\subsection{Dificuldades Apresentadas com o Uso do Excel na Educação}

A pergunta de número um (01), teve como objetivo identificar os saberes ausentes na vida profissional dos professores, no qual os impossibilitam a utilização do Excel no ensino da Matemática, na sua prática docente. De acordo com Silva (2005), a ausência de saberes pode derivar tanto da experiência pessoal quanto da experiência com os componentes curriculares da formação inicial ou das ferramentas informáticas.

Ao analisar as informações fornecidas pelos participantes da pesquisa nesta questão, de modo geral, percebeu-se a ausência de saberes para manipular os recursos 


\section{CBIE-LACLO 2015}

Anais dos Workshops do IV Congresso Brasileiro de Informática na Educação (CBIE 2015)

básicos da ferramenta computacional, entre eles: aplicação de fórmulas disponíveis pelo Excel, a construção de gráficos e tabelas, no ensino de conceitos estatísticos. O fato de possivelmente não terem visto em sua formação a possibilidade prática de situações de como ensinar com essa ferramenta justificaria tal fato.

A segunda questão teve como objetivo identificar as saídas encontradas pelos docentes, no seu exercício da profissão, para ensinar Estatística (Tratamento da Informação), sem o uso do Excel.

Diante das dificuldades apresentadas relacionadas ao uso didático e técnico da ferramenta, a maioria dos professores apresentou como saída o uso de métodos tradicionais. Tal saída corresponde a dizer que o professor somente ensina o que sabe e como sabe, caracterizando uma questão a ser analisada no curso de formação.

A ausência dos saberes docentes informáticos, além de serem destacados como o mais importante para os professores de Matemática, poderia dar-lhes condições de planejar aulas abordando os conceitos estatísticos e utilizar o potencial técnico dos recursos dos programas disponibilizados pela ferramenta (SILVA, 2005).

A terceira questão teve como propósito identificar nos entrevistados, qual a consequência em não saber utilizar o Excel para a execução do seu trabalho docente, com uso da ferramenta em destaque.

As respostas apresentadas indicaram resistência ao uso, por insegurança ou condições de trabalho. Acrescentaram ainda que o uso do Excel possibilitaria tornar suas aulas mais dinâmicas na apresentação de conteúdos voltados ao Tratamento e Análise de Dados, e consequentemente, os alunos passariam a participar de forma mais ativa ao poder trabalhar de forma mais concreta tanto no que concerne a representação desses dados, tanto no processo de interpretação dos mesmos, visto que o uso do livro didático para a apresentação do conteúdo, pode não despertar tanto interesse, já que os jovens, em sua grande maioria, manipulam dispositivos tecnológicos em processo de aprendizagem autônoma ou guiada.

A questão de número quatro (04) teve como propósito, identificar se os professores consideravam existir alguma diferença em utilizar ou não o Excel, no ensino de Estatística. Observou-se que a maioria dos professores reconheceu o Excel como uma ferramenta que faz a diferença entre o êxito do aluno na aprendizagem e auxiliar na dificuldade dos alunos em aprender Estatística, interpretar e construir gráficos, além de interpretas cálculos.

Apesar de não utilizarem o Excel, a quinta e última pergunta, tinha como propósito saber se os docentes utilizavam algum outro software para o ensino no ensino da Matemática. Constatou-se que os professores não utilizam o Excel, mas aplicavam outros softwares para o ensino de outros conteúdos.

Como apresentado por Oliveira (2008, p. 61), "é preciso que o docente em formação tome consciência das dificuldades inerentes ao uso educacional da TI e busque meios para usufruir destas potencialidades, de modo a contribuir para sua formação". Essa consciência é perceptível a partir da análise das respostas dos 04 participantes na quarta questão, que não utilizam o Excel, mas recorrem a outros softwares na sua prática, mas que não utiliza o Excel, por falta de conhecimento de como manipular a ferramenta na educação.

Os saberes ausentes na formação inicial dos professores (SILVA, 2005), influenciam a metodologia aplicada em sala de aula, levando professores a rejeitarem as 


\section{CBIE-LACLO 2015}

Anais dos Workshops do IV Congresso Brasileiro de Informática na Educação (CBIE 2015)

tecnologias presentes nas escolas, mesmo estas fazendo parte de um processo que visa melhorar a qualidade do ensino-aprendizagem.

\subsection{Saberes Docentes com o Uso do Excel na Educação}

Para fazer uso das tecnologias disponíveis nas escolas, os professores recorrem a saberes que não foram construídos em sua formação inicial. A incorporação das tecnologias de informação na prática docente passa a exigir destes, conhecimentos aos quais não tiveram acesso na formação inicial (SILVA, 2005).

Essa afirmação justifica-se na resposta apresentada pelo E8, apresentada na questão 02 (dois), ao afirmar que aprendeu a utilizar a ferramenta sozinho, saberes estes ligados a área da informática, tendo que relacionar o programa Excel para tratar os conceitos em Estatística, entre eles destacam-se aqueles apresentados pelo entrevistado e que correspondem aos destacados nos PCN. Ao mesmo tempo, pode-se levantar também a habilidade e competência do professor em formação para usar o Excel e outros programas no ensino-aprendizagem de Matemática.

Pode-se pressupor, que a formação inicial foi o período que este professor teve para tentar acertar ou errar em sua aprendizagem, levando para o exercício docente o uso de ferramentas em que estava mais seguro em situações de ensino.

\section{Considerações Finais}

Os resultados desta pesquisa apontaram a necessidade de uma formação inicial básica e avançada para aplicação do Excel e os conceitos matemáticos relacionados para o tratamento da informação. Recomenda-se que ações sejam realizadas neste sentido, pois a ausência de conhecimento em como manipular as ferramentas em situações de ensino prejudica os estudantes de Licenciatura em Matemática e aos seus educandos. Há de se repensar a prática e seus conhecimentos correlatos dos programas informáticos para colaborar no sentido de buscar uma melhor atuação em sala de aula do docente em formação, contribuindo com resultados significativos na aprendizagem dos alunos.

A ausência de experiência com a ferramenta no suporte ao ensino-aprendizagem com os professores em formação foi considerada elemento responsável por impossibilitar o seu uso pelos professores universitários. Diante das falas dos professores em formação foi possível destacar o reconhecimento da importância, em usar o Excel no ensino aprendizagem de Estatística. Destacam que a incorporação das ferramentas informáticas no Tratamento da Informação, quando aplicadas em sala de aula favorecem o processo de ensino-aprendizagem.

Esta pesquisa teve por objeto de estudo, os saberes necessários ao repertório docente para o uso do Excel na aprendizagem de Estatística. Partindo-se do questionamento sobre o que os professores, que trabalham com o Excel, tiveram que aprender para ensinar Estatística com esta ferramenta aos seus alunos e que dificuldades os limitam para aplicar o Excel em sua prática.

Como desafio da pesquisa, destaca-se a busca por um número representativo de estudantes que dominassem esta ferramenta. No entanto, os resultados possibilitaram investigar a ausência deste saber, não frustrando a pesquisa com seus dados.

Os professores em formação que desejam usar o Excel, mas não vivenciaram experiências na graduação com esta ferramenta no suporte ao ensino-aprendizagem, deixam claro que reconhecem a ausência de saberes para o potencial técnico da ferramenta para a prática pedagógica, saberes estes necessários ao seu repertório e sua relação com o exercício da profissão na área do conhecimento matemático.

Como trabalho futuro, recomenda-se investigar como os professores de curso de formação na graduação da Licenciatura em Matemática tratam a tecnologia informatizada 


\section{CBIE-LACLO 2015}

Anais dos Workshops do IV Congresso Brasileiro de Informática na Educação (CBIE 2015)

no processo de formação profissional dos estudantes que se encontram na formação inicial, refletindo assim, em sua atuação profissional em sala de aula.

\section{Referencias}

Bardin, L. (1988). “Análise de conteúdo”. Lisboa, Portugal: Edições 70.

Brasil. (1998). "Parâmetros Curriculares Nacionais: Matemática". Secretaria de Educação Fundamental - Brasília: MEC/SEF.

Corrêa, A. A. (2013). "Saberes docentes e o ensino da estatística: considerações sobre a ação pedagógica”. Revista Espaço Pedagógico, v. 20, n. 2.

Campello, Ermínia et al. (2014). "Utilizando recursos de informática: o Excel, como estratégia de ensino-aprendizagem de certos conteúdos matemáticos". Disponível em: $<$ http://www.mat.ibilce.unesp.br/XVIIISemat/Mini-

Cursos/RESUMOS/MT3.pdf $>$ Agosto.

Ferreira, Marcio Violante. (2014). "Um estudo da aplicação da planilha do Excel no ensino de matemática financeira". Disponível em: $<$ http://limc.ufrj.br/htem4/papers/71.pdf $>$ Setembro.

Gil, Antonio Carlos. (2012). "Métodos e técnicas de pesquisa social". 6. ed. São Paulo: Atlas.

Guimarães, G. (2012). "O movimento dos saberes: contribuições conceituais de Transposição Didática e Transposição Informática". In: XVII Congresso de Ciências da Comunicação na Região Sudeste, Ouro Preto, Minas Gerais.

Lopes, C. A. E. (1998). A Probabilidade e a Estatística no Ensino Fundamental:uma análise curricular. Campinas, SP: Faculdade de Educação da UNICAMP. 125p. (Dissertação, Mestrado em Educação).

Pereira, M. L. D., et al. (2014). "Uso do aplicativo Microsoft Excel para potencializar o estudo sobre a Distribuição de Probabilidade Normal nas aulas de Estatística". Disponível em: <http://www.gestaouniversitaria.com.br/artigos/uso-do-aplicativomicrosoft-excel-para-potencializar-o-estudo-sobre-a-distribuicao-de-probabilidadenormal-nas-aulas-de-estatistica--2> Setembro.

Pimenta, Selma Garrido; Lima, Maria do Socorro Lucena. (2012). "Estágio e docência". $7^{\mathrm{a}}$ ed. Cortez Editora.

Prietch, S. S., et al. (2009). "Levantamento sobre Disciplinas de Informática em Cursos de Licenciatura e Considerações a respeito da Formação Docente e o Uso da Informática nas Escolas". I ENINED-Encontro Nacional de Informática e Educação, Cascavel/PR. Anais. Rondonópolis: UFMT/Campus Rondonópolis.

Richardson, Roberto Jarry. (1999). "Pesquisa social: métodos e técnicas". 3. ed. São Paulo: Atlas.

Silva, S. R. F. (2005). “Os saberes práticos docentes em ambiente informatizado: uma análise da reconstrução de professores de Matemática". Dissertação - Mestrado em Educação, Universidade Federal de Pernambuco, Recife, Pernambuco.

Silva, S. R. F. (2012). "Saberes e Conhecimentos Docentes na implementação de Programas de Inclusão Digital em Escolas de Educação Básica em Garanhuns/PE”. Tese de Doutorado. Tese (Doutorado em Educação: Cultura e Cotidiano Escolar)Universidade Estadual do Rio de Janeiro, UERJ, Rio de Janeiro. 
Silva, Josney Freitas; Schimiguel, J. (2013). "O uso das TICs no ensino superior: a integração de diferentes tecnologias à educação estatística". Revista de Produção Discente em Educação Matemática. v. 2, n. 1.

Tajra, Sanmya Feitosa. (2001). “Informática na educação”. São Paulo: Érica.

Tardif, Maurice. (2010). “Saberes docentes e formação profissional”. Rio de Janeiro: Vozes.

Teixeira, Leny Rodrigues Martins; Grigoli, J. A. G.; Lima, C. M. (2002). "Saberes dos professores e ambigüidades da prática docente na rede pública de Campo Grande, (MS)". Associação Nacional de Pós-Graduação e Pesquisa em Educação (Org.), Anais, 25ª Reunião da ANPED, Caxambu, Brasil. 